\title{
ИНТЕРНАЦИОНАЛИЗАЦИЯ ЮАНЯ
}

\author{
ВЛАДИМИР ШАПОВАЛОВ \\ МГИМО МИД России, Москва, Россия
}

\section{Резюме}

В статье рассматривается процесс интернационализации юаня и реализуемые властями КНР в этой связи меры, а также возможные предпосылки расширения использования китайской валюты в международных операциях. Для анализа соответствия статусу международной валюты используются критерии МВФ и SWIFT, а также предложения российских и зарубежных исследователей. Инициируя процесс интернационализации юаня, Китай рассчитывал получить экономические и политические выгоды. Использование национальной валюты в международных транзакциях повышает престиж страны, облегчает проведение отечественными экономическими субъектами трансграничных операций и позволяет оказывать влияние на зарубежных контрагентов. За последнее десятилетие КНР добилась в этом заметных успехов. Более трёх лет китайская валюта входит в число резервных валют МВФ. Вместе с тем доля юаня в международных расчётах и инвестициях не соответствует месту страны в мировой экономике. Соединённые Штаты сохраняют доминирующее положение в международной финансовой системе и не заинтересованы в усилении китайского влияния. Китай сегодня призывает своих основных торговых партнёров создать юаневую зону международных расчётов как альтернативу долларовой международной валютной системе. Несмотря на масштабы экономики КНР, объёмы зарубежных инвестиций и размер внутреннего финансового рынка, интерес к использованию юаня со стороны зарубежных участников остаётся на сравнительно невысоком уровне. Это связано прежде всего с сохраняющимися в Китае ограничениями на движение капитала и затруднённым доступом внешнеэкономических контрагентов к ликвидности и финансовым инструментам в юанях.

\section{Ключевье слова:}

Китай; интернационализация; международная валютная система; международные валютнофинансовые отношения; экономическая политика.

Китай занимает ведущее место среди мировых экономических держав, являясь крупнейшим в мире производителем и экспортёром товаров и услуг. Страна демонстрирует экономический рост даже в условиях пандемии COVID-19, в то время как показатели большинства стран находятся в отрицательной зонеㄹ․ Впечатляю- щие экономические успехи позволили Китаю заявить о своих амбициях в части увеличения использования юаня в международных расчётах и инвестициях. Процесс усиления Китая как международной державы сопровождается призывами к реформированию существующей мировой валютной системы (МВС) и расширению

\footnotetext{
1 IMF World Economic Outlook UPDATE, 2021. https://www.imf.org/en/Publications/WEO/Issues/ 2021/01/26/2021-world-economic-outlook-update (дата обращения: 03.02.2021).

Дата поступления рукописи в редакцию: 15.01.2020

Дата принятия к публикации: 28.09.2020

Для связи с автором / Corresponding author:

Email: vladimir.shapovalov@gmail.com
} 
роли КНР в ней, в том числе за счёт национальной валюты ${ }^{2}$.

История развития МВС показывает, что периоды кризиса и реформирования системы не совпадают [Красавина 2017]. Кризис Парижской МВС длился около 10 лет, Генуэзской - 15 лет, Бреттон-Вудской около 8 лет. С началом глобализации мировой финансовой системы в конце XX века начался кризис Ямайской МВС. Мировой финансовый кризис, наступивший 12 лет назад, продемонстрировал недостатки современной МВС и выявил необходимость её адаптации к новым особенностям глобальной экономики с учётом соотношения сил между крупнейшими экономическими державами. Последствия пандемии COVID-19 для мировых финансов ещё только предстоит оценить.

Добиться полноценного международного статуса валюты удавалось немногим странам. На степень её интернационализации оказывают влияние размер экономики, степень доверия со стороны международных контрагентов и развитость финансового рынка [Frankel 2012]. Сочетание данных факторов позволяет национальной валюте получить широкое распространение за рубежом за различный временной период - от 17 лет в случае немецкой марки до 7 лет для японской иены.

Роль китайской валюты в международном финансовом мире остаётся в центре внимания научного сообщества. Материалы по обозначенной тематике регулярно публикуют российские, китайские, европейские и американские исследователи [Красавина 2017; Кудряшова 2017; Петров, Пилипосян, Ткачёв 2019; Кудряшова, Плешакова 2016; Qingqing Li 2018; Otero-Iglesias 2018; Gjoza 2018]. Оценки современного состояния и перспектив интернационализации юаня различаются - от констатации успехов проводимой китайскими властями политики до критики инициатив в этой сфере.

Для целей настоящей работы применялись критерии интернационализации валюты сообщества всемирных межбанковских телекоммуникаций SWIFT, характеристики свободно используемой в мире валюты Международного валютного фонда $(\mathrm{MBФ),} \mathrm{предложения} \mathrm{российских} \mathrm{и} \mathrm{зару-}$ бежных учёных. В работе использованы статистические данные Банка России, Народного банка Китая, МВФ, SWIFT, Московской биржи, обзоры «Дойче Банка» и «Чайна Констракшн Банка».

\section{1}

Большинство исследователей [Кудряшова 2017; Frankel 2012; Моисеев 2008] отмечают, что для закрепления за валютой статуса международной необходимо совпадение ряда экономических и институциональных факторов.

Среди экономических факторов выделяются ёмкость внутреннего рынка и наличие мощной производственной базы. Страна должна занимать заметное место в мировой экономике и глобальной торговле, а её валюта - широко использоваться зарубежными контрагентами. Кроме того, требуется устойчивое функционирование внутреннего финансового рынка, инфляция должна быть на низком уровне, резервы - значительными, а курс национальной валюты - стабильным.

С точки зрения институциональных факторов должны отсутствовать ограничения на движение капитала и конвертацию валюты [Наркевич, Трунин 2012].

По мнению американских специалистов [Gjoza 2018], среди факторов, влияющих на интернационализацию юаня, можно выделить:

- доступ иностранных инвестиций на локальный фондовый рынок;

- долю юаня в резервах иностранных центральных банков;

- использование китайской валюты для финансирования зарубежных инфраструктурных проектов;

- международную экспансию национальных платёжных систем;

${ }^{2}$ Об усилении роли КНР в формирующемся мировом порядке, о новых центрах силы см.: [Шаклеина 2019; Богатуров 2019]. 
Таблица 1

Объём торгов валютного рынка ПАО Московская Биржа, млрд руб.

\begin{tabular}{|c|c|c|c|c|c|c|c|c|}
\hline & 2013 & 2014 & 2015 & 2016 & 2017 & 2018 & 2019 & 2020 \\
\hline Валютный рынок & 156016 & 228546 & 310837 & 329954 & 347671 & $\begin{array}{l}348369 \\
\end{array}$ & 308274 & 328946 \\
\hline Сделки спот & 57297 & 77798 & 103335 & 107169 & 78380 & 86682 & 67370 & 96942 \\
\hline доллар/рубль & 49327 & 67267 & 92383 & 95530 & 68299 & 72829 & 52210 & 80705 \\
\hline евро/рубль & 6446 & 8954 & 9159 & 10058 & 8502 & 12227 & 13119 & 13408 \\
\hline евро/доллар & 1425 & 1311 & 1075 & 1224 & 1407 & 1371 & 1718 & 2246 \\
\hline юань/рубль & 20 & 252 & 697 & 285 & 122 & 173 & 221 & 318 \\
\hline прочие валюты & 79 & 14 & 20 & 72 & 50 & 83 & 102 & 265 \\
\hline Сделки своп & 98720 & 150748 & 207502 & 222785 & 269291 & 261686 & 240904 & 232003 \\
\hline доллар/рубль & 77899 & 121555 & 165600 & 182804 & 217663 & 204922 & 190418 & 185911 \\
\hline евро/рубль & 19644 & 25758 & 34241 & 33007 & 39728 & 47016 & 38452 & 36663 \\
\hline евро/доллар & 1160 & 3382 & 7496 & 6445 & 11462 & 8714 & 11631 & 8634 \\
\hline юань/рубль & 16 & 53 & 161 & 491 & 370 & 908 & 330 & 668 \\
\hline прочие валюты & - & - & 4 & 37 & 67 & 126 & 74 & 128 \\
\hline
\end{tabular}

Источник: подготовлено автором на основе данных ПАО Московская Биржа. https://www.moex.com/ru/ir/interactiveanalysis.aspx (дата обращения: 03.02.2021).

- развитие финтеха;

- использование китайской валюты в контрактах на сырьевые товары.

SWIFT выделяет три фазы интернационализации валюты по мере её использования: в торговом финансировании, в зарубежных инвестициях, в качестве резервной валюты. МВФ даёт следующие характеристики свободно конвертируемой валюты: она широко используется для платежей по международным операциям и служит предметом активной торговли на основных валютных рынках ${ }^{3}$.

Говоря об успехах интернационализации юаня, можно констатировать прохождение всех трёх фаз согласно критериям SWIFT. Китайская валюта сегодня используется в торговом финансировании, в прямых и портфельных зарубежных инвестициях, а также в качестве резервной валюты. К 2013 г. юань был уже на 8-м месте среди наиболее используемых в мире валют, а в декабре 2020 г. занял 5-е место в совокупной доле международных расчётов ${ }^{4}$.

В 3-м квартале 2020 г. объем китайских юаней в международных резервах центральных банков и денежных властей других стран составил эквивалент 244,5 млрд долларов, или около $2 \%$ от совокупной стоимости всех резервов. Для сравнения: на долю евро в том же периоде приходилось около $19 \%$ международных резервов центральных банков 5 . Что касается зарубежной экспансии китайской платёжной системы, то в настоящее время в качестве косвенных участников China International Payment System (CIPS) подключено 176 организаций из 50 стран $^{6}$.

С точки зрения соответствия критериям $\boldsymbol{M B \Phi}$, несмотря на наличие прямых котировок против валют основных торговых партнёров КНР, юань сегодня не является предметом активной торговли на валютных рынках, значительно уступая по объёмам транзакций традиционным валютам (табл. 1).

\footnotetext{
${ }^{3}$ Статья XXX, пункт f Соглашения Международного валютного фонда. URL: https://www.imf.org/ external/pubs/ft/aa/rus/index.pdf (дата обращения: 03.02.2021).

${ }^{4}$ SWIFT Watch. RMB Tracker. https://www.swift.com/swift-resource/250136/download (дата обращения: 03.02.2021).

5 IMF. Currency composition of official foreign exchange reserves (COFER). URL: https://data.imf. org/?sk=E6A5F467-C14B-4AA8-9F6D-5A09EC4E62A4 (дата обращения: 03.02.2021).

${ }^{6}$ CIPS - China International Payment System - национальная китайская система банковских переводов. http://www.cips.com.cn/cipsen/7052/7057/index.html (дата обращения: 03.02.2021).
} 
Нельзя также говорить о широком использовании юаня для платежей по международным операциям. В декабре 2020 г. на юань приходилось лишь $1,16 \%$ в совокупном объёме международных расчётов за вычетом платежей внутри Еврозоны (для сравнения: доля евро составила $37,5 \%)^{7}$.

Таким образом, сегодня единственной серьёзной альтернативой доллару выступает евро, который за двадцать лет своего существования потеснил американскую валюту по ряду направлений, таких как доля в международных расчётах, резервах центральных банков и международных заимствованиях.

В следующей части статьи анализируются этапы интернационализации китайской валюты и меры, предпринятые властями КНР на этом пути.

Процесс интернационализации валюты является сложным и многоэтапным. Необходимо обеспечить рост доверия зарубежных контрагентов и сформировать у них представление о конкретных преимуществах её использования в качестве средства платежа, меры стоимости и накопления. Наличие соответствующих экономических условий в стране-эмитенте обеспечивает устойчивый спрос на национальную валюту со стороны нерезидентов, что поддерживает её стабильность. Одновременно у международных участников должна быть возможность совершать финансовые операции, доступные им в других валютах [Кудряшова 2017].

Китай начал предпринимать шаги по либерализации использования своей валюты в международных расчётах более 15 лет назад, а глобальный экономический кризис 2008 - 2009 годов привёл к интенсификации данного процесса.
Для целей исследования предлагается условно выделить следующие этапы интернационализации юаня ${ }^{8}$.

1-й этап - создание рынка юаня, обращающегося за рубежом, введение плавающего курса, выпуск юаневых ценных бумаг за пределами КНP. В результате запуска пилотных проектов, разрешающих использование китайской валюты в трансграничных расчётах, образовались пулы юаневой ликвидности и рынок так называемого офшорного юаня, обращающегося за пределами материкового Китая. Юань стал использоваться в трансграничных расчётах китайских контрагентов с их основными региональными торговыми партнёрами. В этот период также произошло зарождение зарубежного рынка облигаций, номинированных в юанях.

В 2002 г. была запущена пилотная программа по допуску квалифицированных иностранных институциональных инвесторов на китайский рынок ценных бумаг (квоты QFII $\left.{ }^{9}\right)$. Спустя год Народный банк Китая назначил первый клиринговый банк для расчётов в юанях за рубежом (Бэнк оф Чайна Гонконг). Затем в Гонконге было разрешено привлекать депозиты в юанях, осуществлять конверсионные операции и выпускать дебетовые и кредитные карточки для физических лиц.

В 2005 г. произошла отмена фиксации курса юаня к доллару США и был введён плавающий режим в рамках колебаний 0,3\% от установленного Народным банком Китая уровня. Официальный курс юаня к основным валютам начал определяться по результатам торгов на межбанковском рынке. Затем была анонсирована программа квот QDII ${ }^{10}$ для квалифицированных китайских институциональных инвесторов, разрешающая инвестиции в облигации и инструменты денежного рынка,

\footnotetext{
7 SWIFT Watch. RMB Tracker. URL: https://www.swift.com/swift-resource/250136/download (дата обращения: 03.02.2021).

${ }^{8}$ Chronology of RMB Going Global. Xinhua http://english.gov.cn/news/top_news/2015/12/03/ content_281475246990434.htm (дата обращения: 18.04.2019).

9 Программа Qualified foreign institutional investor (QFII), направленная на допуск глобальных институциональных инвесторов на китайский фондовый рынок.

10 Программа Qualified domestic institutional investors (QDII) позволяла китайским финансовым учреждениям инвестировать в финансовые инструменты, выпущенные в юанях на зарубежных рынках.
} 
выпущенные зарубежными эмитентами. В 2007 г. был осуществлён первый зарубежный выпуск облигаций, номинированных в юанях (Дим-Сам бондов).

2-й этап - заключение своп-соглашений, запуск валютных торгов юанем за рубежом, допуск иностранных инвесторов на фондовый рынок, запуск системы трансграничных межбанковских платежей, включение юаня в корзину СДР. Данный этап характеризовался заключением Народным банком Китая соглашений о валютном свопе в юанях с центральными банками ряда стран, запуском торгов китайской валютой на зарубежных рынках, прямым допуском международных инвесторов на китайский фондовый рынок в рамках установленных квот. Начала функционировать Шанхайская 3она свободной торговли с облегчёнными правилами обмена валюты и использования юаня во внешней торговле. Был организован мост для торговли акциями между шанхайской и гонконгской биржами. Запущена реализация первой фазы системы трансграничных межбанковских платежей CIPS, предназначенной для оплаты в юанях международных расчётных и клиринговых услуг между финансовыми институтами. Произошло расширение объёма трансграничного финансирования в юанях. Наконец, китайский юань был включён в корзину специальных прав заимствований СДР МВФ наряду с долларом США, евро, фунтом стерлингов и иеной.

В 2009 г. произошёл запуск пилотного проекта по использованию юаня для трансграничных расчётов Шанхая и четырёх городов провинции Гуандун, который впоследствии был расширен для расчётов со специальными административными районами Гонконгом и Макао, а также азиатскими странами.

В рамках Чиангмайской инициативы ${ }^{11}$, предусматривающей предоставление ва- лютных резервов с целью защиты курса национальных валют, Китай в 2010 г. заключил соглашения о валютном свопе с рядом азиатских стран, включая Японию, Республику Корея и 10 стран-членов АСЕАН. В тот же год Китайская торговая система CFETS $^{12}$ начала торговать парой юаньрубль и были запущены торги этой валютной парой на Московской бирже - первом зарубежном рынке для торговли юанем.

В следующем году Народный банк Китая разрешил китайским компаниям осуществлять прямые зарубежные инвестиции в юанях, а также была запущена программа квот RQFII, позволяющая инвестировать в Китай в юанях с зарубежных счетов, отменив требование конвертации иностранной валюты в юани.

В 2012 г. границы колебания курса юаня были расширены до $1 \%$, а совокупный объём соглашений о валютном свопе был увеличен в 2 раза. На межбанковском валютном рынке начались торги валютной парой юань/японская иена, а затем парой юань/австралийский доллар. В 2013 г. Китай заключил соглашение о валютном свопе с Банком Англии.

В 2014 г. начала функционировать Шанхайская зона свободной торговли, возможные границы колебания курса юаня были расширены до 2\%, начались торги валютной парой юань/фунт стерлингов и юань/евро, произошло расширение программы квот RQFII для инвестиционных фондов, зарегистрированных в Гонконге, была запущена программа торговли акциями между Шанхаем и Гонконгом, позволяющая работать на данных рынках через местных брокеров.

В следующем году был разрешён доступ на внутренний межбанковский облигационный и на валютный рынки зарубежным центральным банкам, суверенным фондам и международным финансовым институтам. Народный банк Китая изменил меха-

11 Соглашение о многосторонней инициативе, заключённое в г. Чианг Май (Chiang Mai Initiative) договор между Китаем, Южной Кореей, Японией и странами АСЕАН, предусматривающий предоставление международных валютных резервов с целью защиты национальных валют в случае резкого спроса на долларовую ликвидность. Вступило в силу в 2010 году.

12 Китайская торговая система CFETS (China foreign exchange trade system) основана в 1994 г. в качестве подразделения Народного банка Китая. 
низм определения официального курса юаня, чтобы приблизить его к рыночным реалиям. В Шанхае была запущена первая фаза китайской системы трансграничных межбанковских платежей CIPS. Народный банк Китая продлил действие договора о валютном свопе с Банком Англии с целью развития Лондона как зарубежного клирингового центра по юаням. В Лондоне были выпущены первые облигации, номинированные в юанях. Народный банк Китая отменил ограничения на процентные ставки по депозитам, завершив либерализацию валютного курса.

В 2016 г. Китай расширил доступ инвесторов на свой рынок облигаций, были запущены торги валютной парой юань/корейская вона. В октябре того же года МВФ включил китайский юань в корзину специальных прав заимствований СДР с долей $10,92 \%^{13}$.

3-й этап. Расширение допуска иностранных инвесторов на фондовый рынок, реализация второй фазы системы трансграничных межбанковских платежей. Среди ключевых событий современного этапа можно выделить открытие расчётно-клирингового банка по юаням в Москве и НьюЙорке, расширение доступа иностранных инвесторов на китайский фондовый рынок в рамках квот QFII, решение Народного банка Китая разморозить (дефакто приостановленную с 2015 года в рамках борьбы с оттоком капитала) программу квот RQDII для инвестиций китайских институциональных квалифицированных инвесторов в ценные бумаги иностранных эмитентов, номинированные в юанях ${ }^{14}$, запуск с июня 2018 г. реализации второй фазы CIPS, увеличение в 4 раза квоты на торговлю в рамках торговых мостов Шанхая и Шэньчжэня с Гонконгом, развитие системы торговли ценными бумагами между Лондоном и Шанхаем.

Как видно в части продвижения национальной валюты за рубеж, китайские вла- сти занимали достаточно активную, но в то же время взвешенную и поступательную позицию, в том числе с целью сохранения финансовой стабильности и снижения колебаний валютного курса.

Рассматривая влияние процесса интернационализации юаня на валютный курс, отметим, что изначально увеличение использования китайской валюты сопровождалось постепенным укреплением её курса. С 2014 г. последовал период плавной девальвации и затем - разнонаправленных движений при сравнительно более высокой волатильности.

С 1994 по 2006 г. юань был привязан к доллару США на уровне 8,3 юаня за доллар. С июля 2005 г. была отменена фиксация курса юаня к доллару США и введён плавающий режим в рамках колебаний 0,3\% к основным валютам по результатам торгов на межбанковском рынке. Началось постепенное укрепление курса юаня по отношению к доллару. В мае-июле 2007 г. произошло расширение параметров колебания курса юаня до 0,5\%. К июню 2008 г. курс китайской валюты вырос до уровня 6,8 юаня за доллар в связи с ослаблением валютного контроля и запуском пилотных проектов по использованию юаня для трансграничных расчётов с другими странами.

С апреля 2010 г. по декабрь 2013 г. курс юаня продолжил укрепляться, достигнув уровня в 6 юаней за доллар. Спрос на юани поддерживался за счёт допуска иностранных инвесторов на внутренний китайский рынок, заключения Народным банком Китая своп-соглашений с центральными банками ряда стран, а также в связи с началом использования китайской валюты в зарубежных операциях в рамках Шанхайской зоны свободной торговли. С 2014 г. тенденция сменилась, и в течение трёх лет наблюдалось плавное ослабление

${ }^{13}$ IMF. Currency composition of official foreign exchange reserves (COFER). https://data.imf. org/?sk=E6A5F467-C14B-4AA8-9F6D-5A09EC4E62A4 (дата обращения: 03.02.2021).

14 Циркуляр Народного банка Китая №81 от 3 мая 2018 года. 
до уровня 6,95 юаня за доллар к декабрю 2016 года.

После 2016 г. период плавного движения курса юаня сменился его волатильностью, характеризовавшейся в 2017-2019 годах разнонаправленными движениями. За 2017 г. курс китайской валюты вновь укрепился до 6,3 юаня за доллар. В октябре 2018 г. 1 доллар США котировался на уровне 6,96 юаня. После укрепления до 6,7 юаня в январе 2019 г. китайская валюта вновь ослабла, пройдя рубеж в 7 юаней за доллар в августе 2019 г. В феврале 2021 г. за доллар давали 6,44 юаня.

Помимо влияния на валютный курс, целесообразно рассмотреть и другие последствия интернационализации китайской валюты.

\section{4}

Процесс интернационализации китайской валюты потребовал от Пекина реализации ряда административно-регуляторных реформ. Ожидалось, что данные меры принесут политические и экономические выгоды не только Китаю, но и его зарубежным контрагентам.

Использование национальной валюты во внешнеторговых расчётах и инвестициях повышает статус страны на мировой арене. Национальным корпорациям и инвесторам становится проще осуществлять международную экономическую экспансию. Государство, предоставляющее зарубежное финансирование в национальной валюте, получает возможность оказывать влияние на торговых партнёров и получателей кредитов.

Зарубежным компаниям облегчается доступ на рынок страны, и у них появляется возможность заключать сделки на более выгодных условиях в местной валюте. Одновременно растёт интерес международных инвесторов к внутреннему рынку.

В условиях доминирующего положения доллара США в мировой валютной системе международная торговля и инвестиции зависят от доступа экономических субъектов к долларовой финансовой инфраструктуре и ликвидности. Использование нацио- нальной валюты в зарубежных операциях предоставляет участникам внешнеэкономической деятельности альтернативные способы расчётов и снижает их зависимость от третьих стран. США уже неоднократно использовали текущую финансовую инфраструктуру в политических целях, вводя односторонние ограничения, в том числе в отношении Китая.

Использование национальной валюты при экспорте устраняет необходимость уплаты банковских комиссий за конвертацию. При импорте также снижаются расходы на приобретение и поддержание остатков в иностранной валюте.

При использовании национальной валюты устраняются риски, связанные с колебаниями валютных курсов. Издержки участников внешнеторговой деятельности снижаются в отсутствие необходимости хеджирования рисков.

Создание зарубежного рынка национальной валюты позволяет диверсифицировать источники привлечения средств. Появляется возможность международных заимствований в собственной валюте без риска изменения курса. Для страны-эмитента международной валюты облегчается задача финансирования дефицита платёжного баланса.

Рассмотрение интернационализации юаня будет неполным без освещения негативного эффекта, который может быть вызван этим процессом. Можно выделить следующие отрицательные последствия интернационализации валюты:

- снижение конкурентоспособности национальных производителей;

- повышение волатильности на валютном и финансовых рынках;

- изменение условий привлечения финансирования;

- инфляционные риски;

- снижение возможности контроля со стороны государства.

Повышение спроса на юань со стороны международных участников экономической деятельности может оказать давление на его обменный курс, сделав китайскую продукцию менее конкурентоспособной на мировом рынке. Как следствие, возможен 
перевод производств в другие страны и рост безработицы в Китае. Приток международного капитала извне и его отток при изменении экономической конъюнктуры способны усилить волатильность на внутреннем фондовом и валютном рынках, что создаст угрозу для финансовой стабильности экономики страны.

Привлечение средств с глобальных рынков может происходить на более конкурентоспособных условиях как по стоимости, так и по срокам заимствований, однако в случае некоторых отраслей, пользующихся государственной поддержкой и особыми экономическими привилегиями, возможен обратный эффект.

Монетарные власти страны вынуждены уделять больше внимания контролю за инфляционными рисками вследствие увеличения использования национальной валюты для обслуживания внешнеэкономической деятельности.

Наконец, интернационализация юаня потребует дальнейшей либерализации национальной экономики, снятия торговых и валютных ограничений и, как следствие, снизит степень контроля за экономическими процессами со стороны китайских властей.

Китай сегодня лишь частично соответствует критериям, необходимым для полноценной интернационализации своей валюты. Страна занимает существенное место в мировой торговле, в ней присутствует мощная производственная база, ёмкий внутренний рынок, инфляция находится на низком уровне.

Юань используется в международных расчётах, но его доля в мире не соответствует размерам китайской экономики. Фондовый рынок страны по своим размерам занимает второе место в мире, однако сохраняются ограничения в развитии инфраструктуры и доступе для зарубежных капиталов. Доля иностранных вложений на нём составляет лишь пару процентов. Приход профессиональных инвесторов из-за рубежа не только увеличит спрос на юань, но и повысит качество оценки рисков китайских эмитентов. Основные внешнеторговые партнёры Китая будут стремиться к обеспечению стабильности курсов своих валют по отношению к юаню, в том числе за счёт поддержания резервов в китайской валюте.

Развитие институциональной инфраструктуры в лице Азиатского банка инфраструктурных инвестиций, Нового банка развития и других институтов будет способствовать международному использованию юаня. Это особенно актуально в отношениях с государствами, которые заинтересованы в снижении зависимости от доллара США. Китайские платёжные системы могут взять на себя обслуживание существенной части международных расчётов, прежде всего среди азиатских стран, которые сегодня осушествляются по традиционным долларовым каналам. Использование CIPS pacширит возможность проведения клиринга и расчётов в реальном времени, а также в различных временных зонах. Развитие финтеха, цифрового банкинга и платёжных платформ на базе Alipay и WeChat Pay, приём карт China Union Pay также будут способствовать продвижению юаня в мире.

Будучи крупнейшим в мире импортёром природных ресурсов, Китай мог бы повлиять на текущую конфигурацию ценообразования на рынке энергоносителей, особенно если к данной инициативе присоединятся другие крупнейшие импортёры природных ресурсов, такие как Япония и Республика Корея. В марте 2018 г. на Шанхайской международной энергетической бирже начали торговаться фьючерсные контракты на нефть в юанях, к которым были допущены иностранные инвесторы. Растущее число африканских стран держат юань в резервах, а Китай выступает основным покупателем их природных ресурсов.

В опросе, проведённом изданием Asian Banker $^{15}$ среди 402 китайских и 117 зарубежных компаний, а также 43 финансовых институтов, относительно результатов и

15 The Asian Banker публикует аналитические материалы по финансовой индустрии с 1996 года. 
перспектив интернационализации юаня большинство участников заявили, что они уже увеличили долю своих расчётов в юанях и планировали продолжать это делать.

Основным драйвером в этом процессе выступает снижение транзакционных издержек, а также возможность получения более выгодных условий в переговорах с контрагентами. На объём привлечения зарубежного финансирования в юанях влияет выпуск облигаций и размешение юаневых депозитов за пределами Китая. Включение юаня в корзину СДР дало существенный импульс к использованию юаня за рубежом. Повышение степени открытости финансовых рынков за счёт использования систем торговли ценными бумагами и расширения квот для зарубежных инвесторов также оказало позитивное воздействие. Больше половины зарубежных и около трети китайских компаний, согласно опросу, намерены увеличить объём своих зарубежных активов в юанях. Более трети китайских компаний имеют в планах выпуск юаневых бондов на зарубежных рынках ${ }^{16}$.

Китаю удалось показать серьёзные успехи в интернационализации своей валюты. Юань сегодня используется в торговом финансировании, в зарубежных инвестициях, а также в качестве резервной валюты. В то же время нельзя утверждать, что он достаточно широко используется для платежей по международным операциям.

Основной упор в интернационализации своей валюты Китай сделал на стимулирование расчётов прежде всего с близлежащими странами, своими торговыми партнёрами. Доля китайской валюты в совокупных международных расчётах невелика. Доступ для инвесторов на китайский финансовый рынок всё ещё носит ограниченный характер, а юань не является предметом активной торговли на мировых валютных рынках.
Для увеличения степени интернационализации юаня Китаю можно рекомендовать обратить внимание на следующие направления:

- обеспечение стабильности экономики и финансового сектора;

- развитие финансовой инфраструктуры для проведения расчётов в юанях;

- продвижение использования юаня во внешнеторговых контрактах;

- проведение работы с зарубежными центральными банками с целью увеличения доли юаня в резервах и обеспечения финансовой стабильности;

- оказание технической помощи контрагентам в переходе на китайские системы расчётов;

- развитие зарубежного рынка облигаций, номинированных в юанях;

- стимулирование использования юаня для ценообразования и проведения транзакций в таких секторах, как энергетика и сельское хозяйство;

- проведение международных мероприятий информационного характера с целью популяризации юаня;

- идентификация и устранение законодательных и иных барьеров.

Китаю также необходимо продолжить экономические реформы и стимулировать развитие внутреннего финансового рынка и его инфраструктуры. Кроме того, в процессе либерализации рынка государству надлежит быть готовым к повышению волатильности курса валюты и возможному снижению конкурентоспособности национальных производителей. Экономические преимущества интернационализации национальной валюты, связанные прежде всего с расширением возможностей и снижением стоимости привлечения финансирования, также накладывают на государство ряд обязательств в части обеспечения доверия международного сообщества к проводимой экономической политике.

\footnotetext{
16 Renminbi Internationalization Report 2019. New Inroads, New Prospects. Asian Banker и China Construction Bank http://www.ccb.com/cn/ccbtoday/news/upload/20190522_1558523233/ 20190522185854455444.pdf (дата обращения: 03.02.2021).
} 
Финансовые власти России на протяжении последних ряда лет уделяют особое внимание вопросу использования национальных валют во внешнеэкономических операциях. Опыт Китая, как ведущего торгового и стратегического партнёра Москвы, может быть востребован при разработке мер в части стимулирования использования рубля в международных расчётах и снижения зависимости российских участников внешнеэкономической деятельности от финансовой инфраструктуры и валют третьих стран.

\section{Список литературы}

Богатуров А.Д. Китайский угол в миросистемном управлении // Полис. Политические исследования. 2019. № 5. С. 85-95.

Красавина Л.Н. Реформы мировых валютных систем: ретроспективный и актуальный анализ // Деньги и Кредит. 2017. № 4. С. 14-23.

Кудряшова И.В. Китайский юань как мировая валюта: императивы и реальность // Мировая экономика и международные отношения. 2017. № 9. С. 36-44.

Кудряшова И.В., Плешакова М.В. Необходимость и иерархия международных валют // Финансы и Кредит. 2016. № 35. С. 49-60.

Кудряшова И.В. Роль организационных и институциональных условий в процессе формирования современных мировых валют // Финансы и Кредит. 2015. № 40. С. 44-50.

Моисеев С.Р. Рубль как резервная валюта // Вопросы экономики. 2008. № 9. С. 4-21.

Наркевич С.С., Трунин П.В. Резервные валюты: факторы становления и роль в мировой экономике. М.: Институт Гайдара, 2012. С. 136.

Петров М., Пилипосян А., Ткачев В. Китай: обретение финансовой власти // Международные процессы. 2019. Т. 17. № 3 (58). С. 6-20.

Шаклеина T.A. «Дилемма Америки» в формировании современного мирового порядка // Международные процессы. 2019. Т. 17. № 4 (59). С. 36-48.

Frankel J. Internationalization of the RMB and Historical Precedents // Journal of Economic Integration. 2012. Vol. 27. No. 3. P. 329-359.

Gjoza E. RMB Internationalization: Implications for U.S. Economic Hegemony. Belfer Center for Science and International Affairs. Harvard Kennedy School. 2018. URL: https://www.belfercenter.org/ publication/rmb-internationalization (дата обращения: 09.02.2021).

Qingqing Li. An Analysis of RMB Internationalization. Simon Fraser University, Vancouver, Columbia, Canada. 2018. P. 249-255. URL: http://www.scholink.org/ojs/index.php/rem/article/view/1541/1692 (дата обращения: 09.02.2021).

Otero-Iglesias $M$. Renminbi internationalisation: stuck in mid-river - for now. Elcano Royal Institute. 2018. URL: http://www.realinstitutoelcano.org/wps/wcm/connect/4da79f91-0b4a-4dd4-a01803c64a7474db/ARI84-2018-Oterolglesias-Renminbi-internationalisation-stuck-mid-river-for-now. pdf?MOD=AJPERES\&CACHEID=4da79f91-0b4a-4dd4-a018-03c64a7474db (дата обращения: 18.09.2019).

\section{YUAN INTERNATIONALIZATION STATUS AND PERSPECTIVES}

\section{VLADIMIR SHAPOVALOV}

MGIMO University, Moscow, 119454, Russian Federation

\section{Abstract}

The article provides information about renminbi internationalization stages, actions taken by Chinese authorities in this field as well as suggests possible ways for further increasing usage of the currency in international operations. The analysis is based on international currency criteria used by IMF and SWIFT and well as suggestions of Russian and foreign researchers. Launching the process of renminbi internationalization China was looking to achieve a number of economic and political goals. Usage on the 
national currency in international operations increases the country's prestige in the world, facilitates international transaction for domestic economic actors and allows influencing foreign counterparts. China achieved significant success in internationalizing its national currency in the past decade. Yuan has been part of IMF reserve currencies for more than three years. However, the share of renminbi in global settlements and investments is still moderate and does not correspond to the size of the country's economy. The USA maintains their dominant role in the world's financial system and is not interested in allowing China to increase its global influence. China is inviting its key trading partners to create yuan based international transactions system as an alternative to the US dollar. Despite the scale of the economy, volume of foreign investments and size of the internal securities market - international participants show relatively low interest for renminbi usage. Comparison of the anticipated goals and actions taken and with the current outcomes allows suggesting conceding amendments to the strategy of increasing renminbi usage in the world. This can be achieved by removing restrictions for international capital movements and facilitating access to yuan liquidity and instruments for international participants.

\section{Keywords:}

currency internationalization; China; international monetary system; economic development; economic policy.

\section{References}

Bogaturov A. (2019). Kitajskij ugol v mirosistemnom upravlenii [Chinese angle in the world-system management]. Polis. Political Studies. No. 5. P. 85-95.

Frankel J. (2012). Internationalization of the RMB and Historical Precedents. Journal of Economic Integration. Vol. 27. No. 3. P. 329-359.

Gjoza E. (2018). RMB Internationalization: Implications for U.S. Economic Hegemony. Belfer Center for Science and International Affairs. Harvard Kennedy School. 2018. P. 48. https://www.belfercenter. org/publication/rmb-internationalization laccessed: 09.02.2021).

Krasavina L.N. (2017). Reformy mirovykh valyutnykh sistem: retrospektivnyy i aktual'nyy analiz. [Reforming the world financial system: retrospective and current analysis]. Den'gi $i$ Kredit. No. 4. P. 14-23.

Kudryashova I.V. (2015). Rol' organizatsionnykh i institutsional'nykh usloviy v protsesse formirovaniya sovremennykh mirovykh valyut [The Role of Organizational and Institutional onditions in the Process of Forming of the Current Global Currencies]. Finansy i Kredit. No. 40. P. 44-50.

Kudryashova I.V. (2017). Kitayskij yuan' kak mirovaya valyuta: imperativy i real'nost'. [Chinese Yuan as a World Currency: Imperatives and Realities]. Mirovaya ekonomika i mezhdunarodnyye otnosheniya. No. 9. P. 36-44.

Kudryashova I.V., Pleshakova M.V. (2016). Neobkhodimost' i iyerarkhiya mezhdunarodnykh valyut. [World Currencies: Comparative Analysis in Context of Monetary Functions]. Finansy i Kredit. No. 35. P. 49-60.

Moiseyev S.R. (2008). Rubl' kak rezervnaya valyuta. [Rouble as a Reserve Currency]. Voprosy ekonomiki. No. 9. P. 4-21.

Narkveich S.S., Trunin P.V. (2012). Rezervnyye valyuty: faktory stanovleniya i rol' v mirovoy ekonomike. [Reserve Currencies: Factors of Evolution and their Role in the World Economy]. Moskva. Institut Gaydara. 136 p.

Otero-Iglesias M. (2018). Renminbi internationalisation: stuck in mid-river - for now. Elcano Royal Institute. URL: http://www.realinstitutoelcano.org/wps/wcm/connect/4da79f91-0b4a-4dd4a018-03c64a7474db/ARI84-2018-Oterolglesias-Renminbi-internationalisation-stuck-mid-riverfor-now.pdf?MOD =AJPERES\&CACHEID =4da79f91-0b4a-4dd4-a018-03c64a7474db laccessed: 18.09.2019).

Petrov M., Piliposyan A., Tkachev V. (2019). Kitay: obreteniye finansovoy vlasti [China: gaining financial power]. Mezhdunarodnye protsessy. Vol. 17. No. 3 (58). P. 6-20.

Qingqing Li. (2018). An Analysis of RMB Internationalization. Simon Fraser University, Vancouver, Columbia, Canada. 2018. P. 249-255. URL: http://www.scholink.org/ojs/index.php/rem/article/ view/1541/1692 (accessed 09.02.2021).

Shakleina T. (2019). "Dilemma Ameriki" v formirovanii sovremennogo mirovogo poryadka ["American Dilemma" in the Forging of a New World Order]. Mezhdunarodnye protsessy. Vol. 17. No. 4 (59). P. 36-48. 